\title{
Evaluation of the Kadıköy Hasanpasa Gasworks in the context of sustainable urban design
}

\author{
S. Yuksel \\ Department of Architecture, Dogus University, Turkey
}

\begin{abstract}
Changing and developing technology has influenced the field of industry just as it has in many sectors of the society. Many buildings that were built for industrial purposes have outlived their function. These out-dated buildings have become like broken scabs in our cities, as functional aging appears. These empty and outdated buildings must be refunctionalized so as not to become a security threat to our cities, by becoming hosts to crime scenes and criminals. Refunctionalizing these buildings is crucial to cultural sustainability. The Architects Council of Europe (ACE) policy suggests the following idea about architecture and sustainability: extensions of the life of a current building or adaptation of a building going through functional aging will enable resources to be used more efficiently.

Hasanpasa Gasworks is located in the Kadıköy district of Istanbul. It was established via French, German and Italian technologies in order to meet the gas needs of the Anatolian side of Istanbul in 1891. The Gasworks subsequently operated until it was closed down in 1993. The site and the buildings of the Gasworks were taken under protection and announced as a protected area in 1996. It is among a few important archeological industrial buildings that have survived until today. However, damage was done as some components of the building were detached when the building was being closed down. No steps for implementing cultural sustainability could be taken for Hasanpasa Gasworks as the area it covers is so large, approximately 33,000 square meters. In the present day, isolated gasometer buildings have started to be hosts to crime scenes in our cities. Some parts of Hasanpasa Gasworks were settled by Romanian gypsies. Every passing day is witnessing more and more destruction to the building. In this sense, it becomes compulsory to evaluate Hasanpasa Gasworks together with
\end{abstract}


its environment within the concept of sustainability and to bring it into use again, to put more functions on it and in this way to turn it into a habitable place for the city and society.

In this study, historical and cultural accumulation of Hasanpasa Gasworks will be considered, and it will be analyzed together with the district of Kadiköy Hasanpasa. Refunctionalization solutions will be presented in accordance with the environmental requirements.

Keywords: sustainability, urban design, refunctioning, gasworks, Hasanpasa.

\section{Introduction}

There is a mutual interaction between the cities and the societies that they accommodate. The dynamics in the social structure result in the transformation of urban spaces, while the problems in the urban environment affect the lives of people. Therefore, cities are organisms that are continuously developing and changing. Having considered the fact that the majority of populations live in urban environments, how significant the effects of the urban areas are on the quality of lives of the people has become apparent.

The elevation of the quality of life in cities is citizens' right. The notion of sustainability, which targets the existence of societies in coming centuries, should be handled along with the concepts of livability and quality of life, particularly in the context of urban design. Nowadays, the notion of sustainability has started to accentuate the idea of living simply by enlarging its scope to the concept of sustainable societies. The sustainable urban environment is accurately defined in the Architects Council of Europe (ACE) book titled "Architecture and Quality of Life" as: The sustainability of the public and private buildings and the safety of the public spaces have an enormous impact on the prosperity of citizens and hence on the structure of society. Therefore, sustainability must be taken into consideration in the development of the living environments [1].

\section{The status of the industrial buildings in the historical process}

Technological developments have caused changes in the industrial field as they have in many other areas. The industrial buildings, which have lost their functions due to developing technology, have been evacuated and abandoned. The re-functioning and re-use of these buildings has become a problem in the last half of the century. The majority of these buildings has not been preserved and thus has been lost since the conservation of the industrial areas in Turkey is a very new issue. Ignoring their historical significance, the fact that they are considered within urban renewal projects has further contributed to their rapid deterioration. The number of industrial buildings in Istanbul was 221 in total, 187 of these buildings being on the European side, 33 of them on the Asian side and 1 on the island of Buyukada. Only 25 industrial buildings have survived 
until today [2]. This shows how neglected the industrial buildings have been. Nonetheless, industrial buildings have very important assets from the perspective of the history of technology, architecture and culture. The conservation and transmission of industrial areas to successive generations is a matter that should be tackled in the context of sustainability.

The Architect Council of Europe (ACE) also pointed out that cities are faced with problems such as "conserving and developing the architectural cultural heritage" and emphasized that sustainable urban development should contribute to the projects regarding transforming and using the areas and the buildings "especially those of abandoned industry" at the meeting in Brussels the city of Belgium in 2008 [3].

\section{The gasworks}

The facilities that produce and store gas, which is obtained from the coalmines, to be used for heating and lighting in urban areas are called Gasworks. The purpose of constructing Gasworks was to illuminate the palaces and the streets. The lamps originally were lit with candles that were at the end of long sticks. This was done by officials every evening and in the morning the gas valves were closed. The gas has lost this function when electricity started to be used. Then the gas was utilized in the houses as natural gas. Later on the gas lost its function completely and the production of the Gasworks ceased.

The gas was first obtained at the end of the $18^{\text {th }}$ century by a Belgian chemist whose name was Jan Pieter Minckelers. It was used to illuminate many cities, mainly in Paris and London starting from the 1820's [4].

The first use of gas was realized in 1856 for lighting of Dolmabahce Palace. Dolmabahce Gasworks was founded with the technology from England. The gasworks facilities were installed at the back of the palace under the reign of Sultan Abdulmecit. Due to excess production, gas was given to nearby neighborhoods such as Istiklal Street and the Pera District. Only one gasometer remains from the Dolmabahce Gasworks at the present. The idea of transforming the gas holder to a theater came up but it could not reach a tangible result [5].

The second usage of gas in Istanbul was the case of Kuzguncuk Gasworks, which was built to illuminate the palace of Beylerbeyi. The gasworks, which was founded in 1865, has also served the local neighborhood. The facilities services' were stopped in 1940; the metal parts of it were moved to Hasanpasa Gasworks. The stone walls, as well as the pool, of the main and auxiliary building have remained until today. The stone walls and the pool of Kuzguncuk Gasworks have been registered as a first grade historical building by the Supreme Council of Monuments. The facilities of the Kuzguncuk Gasworks, which cover an area of 10,000 square meters, have been leased for 49 years by the Union of Mulkiyeliler (the University Students of Political Science in Ankara) to be used as a Cultural Center [6].

Yedikule Gasworks was the first in Istanbul to be established specifically for the social services in 1880. The previous gasworks were established to illuminate the palaces. All previous gasworks had been established for governmental 
buildings. However, Yedikule Gasworks, which was built on an area of 52,000 square meters, was built for lighting the streets of Istanbul, a direct benefit and service to the people. Yedikule Gasworks was closed in 1993, after an impressive 113 years of serving the community. Unfortunately, today Yedikule Gasworks stand in ruin as attempts to convert the buildings and site into a cultural center have not been achieved [7].

\subsection{Kadıköy-Hasanpasa Gasworks}

Istanbul is a city that had been the capital of Roman, Byzantine and Ottoman Empires, also it is a city that has land on Asian as well as the European Continents. Kadıköy, with historical and cultural value, is a district located in the Asian Region of Istanbul. Kadıköy, whose antique name was Khalkedon, is located on the coast of Sea of Marmara. It is a central district that has land, sea and railway transportation facilities. It is well developed in the areas of education, culture, health and trade. Hasanpasa is an old resort district of Kadıköy that developed after the construction of gasworks. Its population started to increase and migration began after the construction of gasworks. This area was developed as an industrial zone because of the gasworks as well as the establishment of mechanics, serving automotive industry.

Hasanpasa Gasworks was built on an area of 33,000 square meters in Hasanpasa district by French and German engineers. Hasanpasa Gasworks, the construction of which started in 1887, begun production in 1891. It was granted to French administration for fifty years. The contract was renewed with the Republic Government of Turkey in 1924. It was converted to a single company being bought by the Yedikule Gasworks in 1926. It was then sold to the Istanbul Electricity Company in 1931. After continuing its existence independently between 1938 and 1944, it was then transferred to the Istanbul Electricity Tunnel and Tram Business (IETT) in 1945.
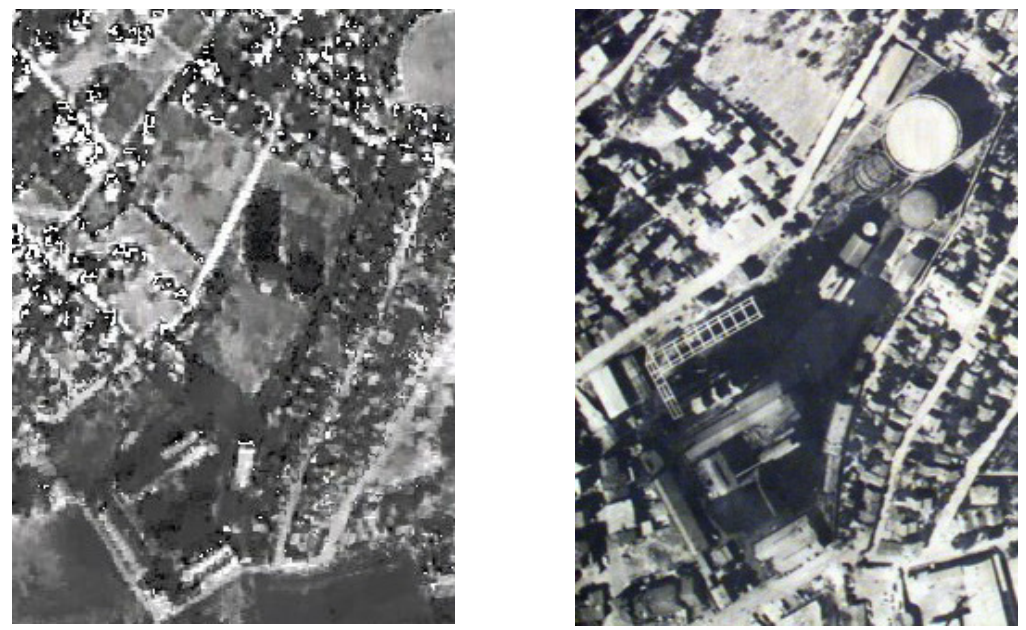

Figure 1: $\quad$ The view of Hasanpasa Gasworks area in 1946 and 1966 [8]. 


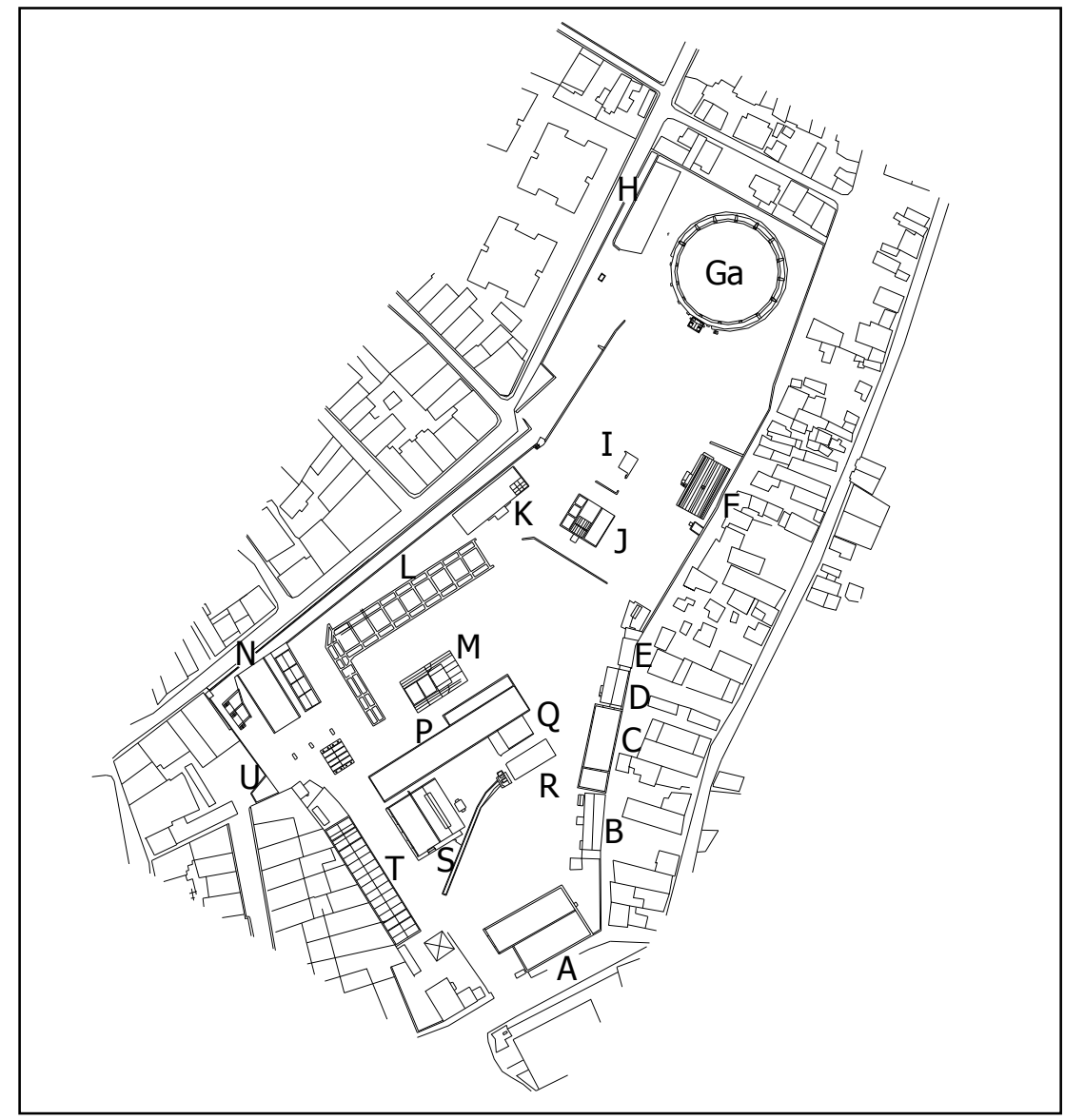

Figure 2: $\quad$ The site plan of Hasanpasa Gasworks.
A - Hall and Storages
B - Storage
C - Gas Counter Production
Plant

D - Showers

E - Fire Station Building

F - Compressor Building

$\mathrm{Ga}$ - Gasometer

$\mathrm{H}$-Brick Storage

I - Compressor Building

$\mathrm{J}$-Water Gas Production Plant

$\mathrm{K}$ - Brick Storage
L - Coal Storage

$\mathrm{M}-$ Oven

$\mathrm{N}$ - Percolator

$\mathrm{O}$ - Cooler

$\mathrm{P}$ - Coal Storage

$\mathrm{Q}$ - Compressor Building

$\mathrm{R}$ - Oven

$\mathrm{S}$ - Percolator

$\mathrm{T}-$ Storage Building

$\mathrm{V}$ - Lodging house

Figure 3: The list of the buildings of the gasworks. 
The number of total ovens was increased up to ten by adding two new ovens in 1948. Rigged with new oven battery and gas releasing devices in 1957, a surplus of gas production above the demand of the Asian side of Istanbul was realized. As a result, a significant savings on coal consumption was provided. The gaswork's production ended and it was closed in 1993 as the increasing use of LPG instead of gas as well as decrease in demand for gas [9, 10].

Following the closing of the Hasanpasa Gasworks, some mechanical items of the building's insides had been removed and evacuated as observed in other industrial buildings in Turkey. The Gasworks, whose two gasometers were stripped off, has been damaged and continued to see damage until the usage of the building in an urban context came to agenda. Under these circumstances inhabitants of the district established the "Gasworks Environmental NonGovernmental Organization Volunteers" to protect the Gasworks and to provide its re-use for the public interest. The Gasworks has been taken under protection by Cultural and Natural Heritage Preservation Council Number II. Despite this decision, in 1996, with the support of this organization, IETT began the destruction of Hasanpasa Gasworks. Their actions were stopped by legal action. It was then decided to re-function the Gasworks as a cultural center by the Preservation Council in 1998. 'The Protection and Reuse Preliminary Project' for Gasworks was prepared by Istanbul Technical University. The proposal was approved by the Preservation Council in 2001, yet no action for implementation has been undertaken. It is also thought provoking that the implementations planned within the scope of Istanbul's 2010 European Capital of Culture events have not yet started $[11,12]$.

Hasanpasa Gasworks, accommodating a gasometer, as well as other gasworks installations, has become abandoned buildings that threaten the environmental safety. Some of the buildings that remain to present day have been used as storage warehouses by IETT, while some of the abandoned buildings are occupied by Gypsies. Buildings are being increasingly damaged every single day by uncontrolled interventions. Illegal building formations have reached up to the wall of Gasworks. The status of Hasanpasa Gasworks, which is one of the most significant industrial heritages on the Anatolian side of Istanbul is rather worrisome. The municipality gave permission for the use of the vicinity of Gasworks for artistic activities in 2008. An art festival organized by Trans Yapit was realized between the dates 30 September - 19 October in 2008. In this festival, which was jointly organized by Berlin Iacht e.V., an art and cultural association of Berlin, various activities were realized. Participation of residents living nearby was particularly remarkable. Another activity was planned for 2009; however, it was not successful due to problems regarding the organization.

The list of the buildings of gasworks that still exist today is depicted in Figure 2 [13].

\section{Conclusion}

Hasanpasa Gasworks is an important source since it describes the industrial history as well as Turkish modernization. It is a building that has contributed to 


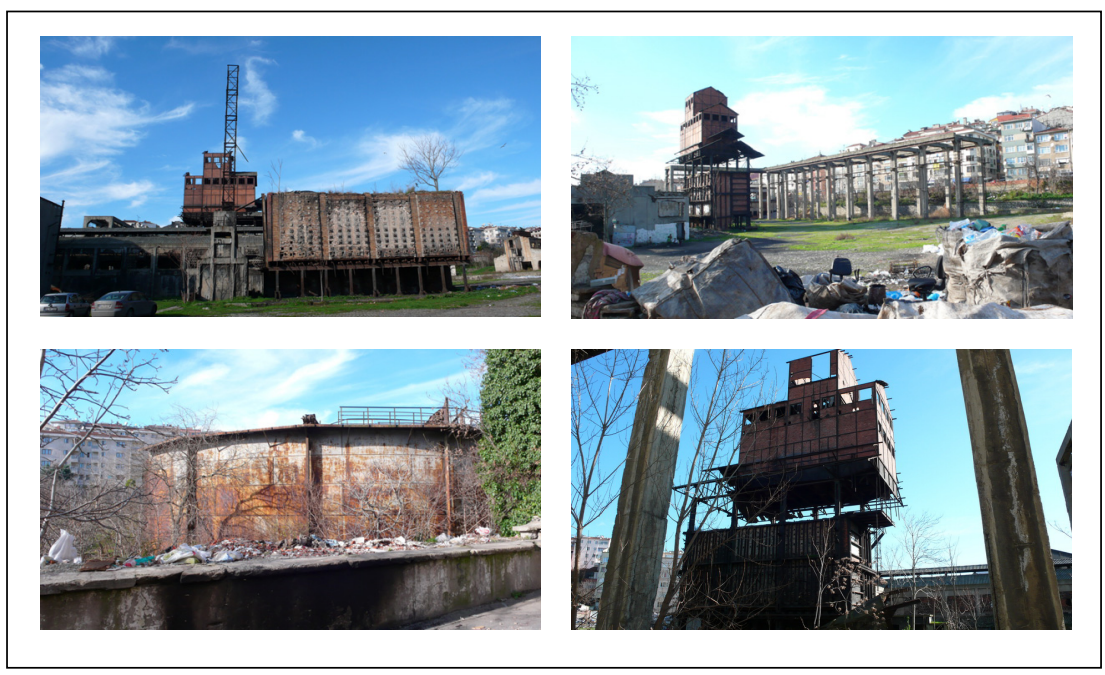

Figure 4: $\quad$ View from the Hasanpasa Gasworks area [14].

the formation of the city, and the collective memory, and thus it should be preserved. It is necessary to refunction and transmit it to future generations so as to provide its sustainability in all fields.

People from different cultures such as Macedonians, Albanians, people from Sinop, Kastamonu and Gypsies live in Hasanpasa district. The faculties of Art and Design and Vocational High Schools of two different private universities that have moved here in recent years will begin to bring a different dimension and social life to the region. New users and new requirements have already brought some changes into the environment. Different cultural and educational levels constitute the social structure of the district.

There is a lack of open public spaces in Hasanpasa area. District inhabitants indicated in interviews that there are no open or closed recreation areas for themselves or for their children. The intense participation in the festival in 2008 is an indicator that shows this demand. One of the common complaints of the district inhabitants is that Gypsies conduct their meetings and weddings in the area.

Hasanpasa has an easily accessible location because of its proximity to $\mathbf{E 5}$ highway and sea transportation. In addition to that, the construction of metro has reached up to this area.

As a result, immediate preventions should be taken for Gasworks area, which is under occupation and intervention every day. The uncontrolled construction and the intervention to the surrounding area must be prevented. The preliminary project, which was prepared in 2001 and approved, should be reconsidered with the participation of different disciplines in line with current environmental conditions. According to the evaluation criteria, urban design studies for sustainable reuse of Hasanpasa Gasworks should go through the following processes: 
- The Gasworks should be considered at the urban scale with its environment.

- The participation of all of the local people should be maintained

- The reuse should be fulfilled in a manner that will transfer the history of Gasworks

- The quality of life should be increased.

-The reuse of the Gasworks should be in harmony with ecological balance

The issue of the reuse of the Gasworks will go through a long process as a part of sustainable urban design. The result will be beneficial at urban, regional and global scales in terms of natural, cultural and economic sustainability. The reuse of Hasanpasa Gasworks with the mixed-use public spaces will greatly provide profound gains to the public.

\section{References}

[1] ACE, www.mo.tr./UIKDocs/acesustainability2009.pdf

[2] Köksal, G., Kaybolan Endüstri Mirasımız veBazı Öneriler. Domus, 8, pp. 52-55,2000

[3] ACE, www.mo.org.tr/UIKDocs/councilcultureconclusions.pdf

[4] Kayserilioğlu, S., \& Mazak, M., Osmanlı'dan Günümüze Havagazı Tarihçesi I.Cilt, İgdaş Yayınları, Ankara, 1999.

[5] Mazak,M., Çağdaş kent olgusu olarak İstanbu'da İlk Aydınlatma Çalışmaları. www.mehmetmazak.com/istanbuldaaydinlatma.html

[6] Mülkiyeliler Birliği Kültür ve Sosyal Tesisleri www.mulkiyeistanbul.org/

[7] Yedikule Gazhanesi, www.dijimecmua.com

[8] The photos from the archive of Yildiz Technical University Faculty of Architecture Department of Restoration.

[9] Cengizkan, A., Fabrika'da Barınmak, Arkadaş Yayınev:Ankara, 2009.

[10] Gazhane Çevre Gönüllüleri, Hasanpaşa Gazhanesi, Papirüs Basım:İstanbul, pp. 15-21, 2003

[11] Aslan,D.,\&Batur, A., Conservation and Re-use of an Industrial Complex. Conversation of the 20th Century Architectural and Industrial Heritage. Icomos Istanbul, pp. 159-163.2005

[12] Sev, A., Sürdürülebilir Mimarlık, YEM Yayınevi: İstanbul, Türkiye, 2009.

[13] The site plan was reproduced by the author from the original survey study prepared by Istanbul Technical University for Kadikoy Municipality.

[14] The photos from Archive of Sen Yuksel 